\title{
Exploiting solvent effects in drug design and optimization
}

\author{
Jean-Francois Truchon ${ }^{1}$, Kristina Grabowski ${ }^{2}$, Barbara Sander ${ }^{2}$, Alain Ajamian ${ }^{3^{*}}$ \\ From 9th German Conference on Chemoinformatics \\ Fulda, Germany. 10-12 November 2013
}

Upon ligand binding, solvent molecules around the binding pocket and the ligand become displaced or rearranged. These desolvation energies can be a significant portion of the total binding energy, and thus represent opportunities for ligand design. Computing desolvation energetics typically requires lengthy simulations, but this talk presents a fast and easy-to-use method (3D-RISM) which computes desolvation energies in minutes, without using explicit simulations. Application to ligand optimization is demonstrated using case studies.

\footnotetext{
Authors' details

${ }^{1}$ Vertex, Laval, H7V 4A7, Canada. ${ }^{2}$ Chemical Computing Group, Köln, 50672,

Germany. ${ }^{3}$ Chemical Computing Group, Montreal, H3A 2R7, Canada.
}

\section{Published: 11 March 2014}

\section{References}

1. Luchko T, Gusarov S, Roe DR, Simmerling C, Case DA, Tuszynski J,

Kovalenko A: Three-dimensional molecular theory of solvation coupled with molecular dynamics in Amber. J Chem Theory Comput 2010,

6:607-624

2. Kovalenko, Hirata F: Self-consistent description of a metal-water interface by the Kohn-Sham density functional theory and the three-dimensional reference interaction site model. J Chem Phys 1999, 110:10095-10112.

Publish with ChemistryCentral and every scientist can read your work free of charge

"Open access provides opportunities to our colleagues in other parts of the globe, by allowing anyone to view the content free of charge."

W. Jeffery Hurst, The Hershey Company.

- available free of charge to the entire scientific community

- peer reviewed and published immediately upon acceptance

- cited in PubMed and archived on PubMed Central

- yours - you keep the copyright

Submit your manuscript here:

http://www.chemistrycentral.com/manuscript/ 